\title{
Teleología y epigénesis: una aproximación a los organismos en la Crítica de la Facultad de Juzgar de Kant*
}

Teleology and Epigenesis: An Approach to Organisms in Kant's Critique of the Power of

Judgment

\author{
Juan Felipe Guevara-Aristizabal ${ }^{\dagger}$ \\ Xóchitl Arteaga-Villamil
}

\begin{abstract}
Resumen
Los diversos cuestionamientos alrededor de qué son los organismos y cómo estudiarlos no sólo han provenido desde la biología, sino también desde el pensamiento filosófico. En este sentido, el análisis de la teleología y las razas humanas, así como de la epigénesis y la Bildungstrieb de Blumenbach en el s. XVIII, ofrece un panorama en el cual el estudio de los seres vivos cimbró la manera en que Kant se encontraba estructurando su empresa crítica, en particular la influencia que esto tuvo en la Crítica de la Facultad de Juzgar, además de las implicaciones y problemáticas que resultaron al intentar posicionar u ordenar lo vivo en el marco que la causalidad y el mecanicismo de la física newtoniana ofrecían. Así, nuestra propuesta reflexiona sobre un diálogo situado y concreto de la mutua influencia que se dio entre la filosofía y la ciencia y cómo esta comunicación abandera una forma legítima y no mecánicamente reducible de estudiar a los organismos.
\end{abstract}

Palabras clave: teleología - epigénesis - organismo - Kant - Blumenbach

\begin{abstract}
Many issues concerning the study of organisms have not come only from biology, but also from philosophical reflections. The analysis of teleology, the human races, epigenesis and Blumenbach's Bilgungstrieb during the $18^{\text {th }}$ century, offers an interesting landscape. Kant's critical enterprise was shaken, particularly in the Critique of the Power of Judgment, by locating and ordering the living within the frame offered by Newtonian mechanics and causality. Thus, our proposal reflects upon a situated and concrete dialogue about the mutual influence played between philosophy and science and how this communication champions a legitimate and non-mechanically reduced way of studying organisms.
\end{abstract}

Keywords: teleology - epigenesist - organism - Kant - Blumenbach

\footnotetext{
* Recibido: 12 de Junio de 2014. Aceptado con revisiones: 20 de Agosto de 2014.

${ }^{\dagger}$ Doctorando del Posgrado en Filosofía de la Ciencia, UNAM, México. Para contactar al autor, por favor, escribir a: juanfgapro@gmail.com.

* Facultad de Ciencias, UNAM, México.

Metatheoria 5(1)(2014): 21-33. ISSN 1853-2322.

(C) Editorial de la Universidad Nacional de Tres de Febrero. Publicado en la República Argentina.
} 


\section{Introducción}

Asociar el análisis filosófico de dos conceptos tan desbordantes como lo son la teleología y la epigénesis con un único autor, Immanuel Kant, podría resultar a simple vista una interpretación sesgada. Sin embargo, hay dos razones relevantes por las cuales decidimos enfocarnos en la obra de este filósofo. Por un lado, los dos conceptos se encuentran entrelazados en su obra, no sólo dentro de la discusión particular de los organismos, ${ }^{1}$ sino también en consideraciones mucho más generales relacionadas con su propuesta epistemológica. Por otro lado, nos interesa resaltar el diálogo profundo que surgió a raíz de su encuentro con los discursos biológicos del s. XVIII -en especial, la embriología- y que repercutió sobre temas como el problema de la unidad de las razas humanas, el desarrollo de la razón, la generación de los organismos, la teoría de la epigénesis y su ulterior acercamiento a la obra de Johann. F. Blumenbach. En este sentido, Kant jugó un cierto papel legitimador de las prácticas biológicas de su época gracias a la riqueza de su análisis en la esfera de lo vivo, el cual apuntaba, principalmente, a las diferencias cruciales entre el estudio de la naturaleza física y la de la vida dentro de un contexto epistemológico. Dichas diferencias serían explotadas tanto por historiadores como filósofos naturales ${ }^{2}$ a lo largo del s. XIX, extendiéndose hasta el XX y con ecos que aún resuenan en el XXI.

El presente trabajo se configura en el marco de dos intereses primordiales. En primer lugar, posibilitar la re-interpretación e, incluso, deconstrucción, desde una óptica contemporánea, de los análisis y preocupaciones kantianas, así como del diálogo que mantuvo con la biología de su época. Nuestro texto se sitúa ${ }^{3}$ desde una óptica que nos permita relacionar un discurso filosófico del siglo XVIII -Kant y su Crítica de la Facultad de Juzgar ([1790] 1987)- con nociones biológicas cuyas controversias se extienden hasta nuestros días, como lo son la teleología y la epigénesis. Podría pensarse que nuestra postura histórica adolece de un presentismo soterrado, tal y como lo manifiesta abiertamente John H. Zammito (2006). Pese a ello, no abandonamos la perspectiva contemporánea puesto que, a través de ella, se pueden abrir compuertas a puntos de vista divergentes que enriquezcan las discusiones en curso -tanto en biología como en filosofía-, sin que ello conlleve a un enjuiciamiento actual de las ideas kantianas. ${ }^{4}$ En segundo lugar, ofrecer un texto que exponga el tejido conceptual propuesto por Kant entre teleología y epigénesis, en el marco de su epistemología y dentro de una obra muy específica, i.e. la Crítica de la Facultad de Juzgar, razón por la cual el número de textos abordados constituye una pequeña muestra dentro del enorme corpus kantiano. Creemos que hay una necesidad tácita de este tipo de aproximaciones en español dado que la oferta actual (bien sea en nuestro idioma o escrita por hispano-hablantes en otros idiomas) se ha concentrado en ofrecer una postura frente a dos debates en curso: por un lado, el grado de influencia que tuvo la embriología en la totalidad de la obra kantiana, y en particular en su sistema crítico (ver Moya 2004, 2005a y 2005b, Rosas 2008); por otro, la actualidad de Kant en las ciencias de la vida (ver Mossio \& Moreno 2010,

\footnotetext{
${ }^{1}$ Kant no utiliza el término organismo en sus obras; en su lugar, se refiere a los seres vivos como seres organizados (organisierte Wesen). No obstante, a pesar de ciertas contingencias históricas y epistemológicas, los dos términos se traslapan conceptualmente. Por tal motivo, dudamos que se caiga en un anacronismo al utilizar, a lo largo de todo el artículo, la denominación de organismos en el contexto de la discusión kantiana.

${ }^{2}$ El uso de historia natural procede del mismo Kant -Primeros principios metafísicos de la Ciencia de la Naturaleza ([1786] 1993, p. 100), así como en los textos sobre raza discutidos a continuación-, quien agrupa dentro de este campo a aquellos estudiosos de los organismos cuya aproximación metodológica se centra en un criterio genealógico, en contraposición a la descripción natural cuyo criterio es la comparación y el hallazgo de semejanzas o diferencias entre los organismos. El uso filosofía natural refiere particularmente a la Naturphilosophie germana.

${ }^{3}$ De manera particular, nos referimos a situar y localizar con base en la perspectiva de Donna Haraway "Situated Knowledges: The Science Question in Feminism and the Privilege of Partial Perspective" (1988), como una alternativa con conocimientos parciales y localizables frente al relativismo y el totalitarismo, donde nuestra propuesta se inserta como una mirada parcial que vive dentro de límites y contradicciones, porque los conocimientos situados son acerca de comunidades, no acerca de personas aisladas, ya que la única forma de encontrar una visión más amplia es ser alguien en particular. Así, proponemos y estamos disponibles ante las conversaciones, conexiones y aperturas que este texto tratado como conocimiento situado posibilita.

${ }^{4}$ Zammito (2006) se presenta como un buen contraejemplo a esta postura. Sus detallados y delicados análisis históricos hacen gala de su destreza y nos ofrecen un panorama muy fino de Kant en tanto figura histórica, aquel situado por completo en su época. Sin embargo, cuando la mirada de Zammito gira hacia el presente, su pluma no duda en afirmar que Kant es irrelevante en las discusiones actuales tanto de biología como de filosofía de la biología gracias a que sus ideas no son susceptibles de ser naturalizadas-asumiendo, por supuesto, que la filosofía contemporánea es una empresa naturalizadora.
} 
Ruiz-Mirazo et al. 2010, Ruiz-Mirazo \& Moreno 2012). No obstante, en ambos casos se han dejado de lado análisis más acotados que sirvan como base o puerta de entrada a aquellos más amplios.

Como podrá verse a lo largo del artículo, hemos utilizado una estrategia de conjunción, en lugar de disyunción, al momento de escribirlo. Es decir, sacrificamos la unidad estilística del texto con el fin no sólo de darle lugar a las dos voces que lo compusieron, sino también de abordar cada concepto desde las problemáticas impuestas por el tratamiento kantiano de los mismos: la teleología, por un lado, es descrita y discutida con minucia y rigurosidad por el propio Kant, de modo que él se encarga de mostrarnos su punto de entrada y apertura así como los conflictos que genera al interior de su sistema; por su parte, la epigénesis la toma del medio académico de su época, incluyéndola de forma directa en sus reflexiones al tiempo que le da su propio toque. ${ }^{5}$ En ese sentido, nuestro texto va reconstruyendo el hilo argumentativo intra-kantiano que lleva a la noción de teleología de la Crítica de la Facultad de Juzgar, ${ }^{6}$ mientras que la epigénesis se reconstruye de manera extra-kantiana, haciendo alusión a las ideas de otros autores del s. XVIII así como a análisis históricos contemporáneos sobre dicho periodo.

\section{Teleología: de las razas humanas a los organismos}

Pese a que nuestra discusión se centra en los conceptos tal y como fueron expuestos por Kant en la Crítica de la Facultad de Juzgar, la noción de teleología no es ajena a su producción pre-crítica; de hecho, una de sus primeras apariciones se encuentra en Teoría Natural Universal e Historia de los Cielos de 1755. Sin embargo, el entrelazamiento clave de teleología y organismo ${ }^{7}$ no llegaría sino hasta la década de $1770,{ }^{8}$ cuando, en el contexto de la preparación y propaganda de su curso de geografía física de 1775 , Kant abordara el problema de las razas humanas y, con él, se adentrara de forma mucho más seria en el terreno de las discusiones embriológicas de su época. Tres serían las publicaciones dedicadas al tema de las razas humanas a lo largo de más de una década en las cuales se plantea y reformula de forma constante la pregunta por el lugar de la herencia y la embriología en dicha temática. No es nuestra intención hacer un análisis exhaustivo de estas incursiones iniciales; más bien pretendemos ofrecer algunos elementos que resultan clave para la exposición de la Crítica de la Facultad de Juzgar.

El primero de ellos se encuentra en el artículo de 1777, "De las distintas razas de seres humanos". 9

En él, Kant dice lo siguiente:

The human being was destined for all climates and for every soil; consequently, various germs and natural predispositions had to lie ready in him to be on occasion either unfolded or restrained, so that he would become suited to his place in the world and over the course of the generations would appear to be as it were native to and made for that place. With these concepts, let us go through the whole human species on the wide earth and adduce purposive causes of its subspecies therein in cases where the natural causes are not easily recognizable and again adduce natural causes where we do not perceive ends (Kant [1777] 2007, p. 90). ${ }^{10}$

\footnotetext{
5 Nuestro texto no se centra en las particularidades de la concepción kantiana de la epigénesis como sí del contexto histórico y los debates en torno a ella. Para el primer punto recomendamos la lectura de Natalia A. Lerussi (2012, 2013).

${ }^{6}$ No queremos que con esta estrategia se entienda que la idea de teleología es original de Kant; por el contrario, él también la retoma de las discusiones filosóficas, particularmente teológicas (esto se puede ver muy bien en la Crítica de la Razón Pura (1781) y en la Crítica de la Razón Práctica (1788)), de su época, en especial de la filosofia de Christian Wolff (van der Berg 2013).

7 Aunque esta es una de las relaciones claves en la presente revisión, reconocemos que la teleología en Kant mantiene lazos mucho más extensos con otros temas de su obra, particularmente en el "Apéndice a la Dialéctica Trascendental” de la Crítica de la Razón Pura (1781) y la idea de una unidad sistemática de la Razón.

8 Algunas consideraciones someras del tema de las razas, pero ligado a la cuestión de las naciones, aparece en las Observaciones sobre el sentimiento de lo bello y lo sublime, de 1764.

9 La primera versión de este texto aparecería en 1775 como parte del anuncio de Kant para su curso de geografía física. La versión publicada de 1777 incluye algunas adiciones así como modificaciones al primero.

${ }^{10}$ Este primer texto sobre las razas de seres humanos no ha sido traducido del alemán al español, o por lo menos no en versiones publicadas bajo algún sello editorial. Dado que sí existen versiones en inglés (una de Cambridge y otra de SUNY), hemos optado por utilizar esta lengua bajo el supuesto de que nuestro público está más familiarizado con ésta que con el alemán; además, hemos decidido utilizar la de Cambridge pues es más fluida para la lectura continua del texto. Tampoco hemos optado por una traducción directa del alemán, pues nuestras habilidades con dicho idioma no están a la altura del desafío, ni por una del inglés al español, pues no nos parece una práctica adecuada dentro del ámbito de la traducción.
} 
En este pasaje se encuentran dos temas de profundo interés para lo que vendrá más adelante. Por un lado, la primera mitad utiliza un lenguaje muy cercano al de las teorías preformistas del s. XVIII, i.e. gérmenes y predisposiciones naturales. Por otro, la segunda mitad pone de manifiesto una cierta dicotomía entre una aproximación que apela a causas finales y otra a causas naturales. Aquí yace la contraposición entre teleología y mecanismo cuyo punto más álgido se encontrará en la antinomia del juicio teleológico -que veremos más adelante cuando hagamos inmersión en la Crítica de la Facultad de Juzgar-.

El texto de 1785, "Determinación del concepto de raza humana", el segundo en nuestra lista, trae una llamativa cita en la cual se resalta la idea de un 'plan en la naturaleza de las criaturas': "La finalidad en una organización constituye el fundamento general del que deducimos una dotación originariamente dispuesta en la naturaleza de una criatura con este propósito y, si este fin sólo fuese alcanzado tardíamente, de semillas increadas" (Kant [1785] 2006a, p. 108, la cursiva es nuestra). ${ }^{11}$ La idea de un plan, aunque éste se encuentre en los organismos, trae a colación la posibilidad de una fuente externa que dicta, impone o introduce aquellos fines para los cuales una determinada criatura resulta adecuada. Ya sea que esta fuente externa sea la Naturaleza o alguna forma de divinidad, el problema que trasiega estas líneas está estrechamente ligado a la eventual determinación de una tal agencia encargada de preconcebir y dictar dichos fines; se trata, pues, de un elemento fundamental que marcará la distancia entre agencia humana y finalidad natural.

Por último, tenemos el artículo de 1788, "Sobre el uso de principios teleológicos en la filosofía". En él encontramos algunas de las ideas más importantes para la construcción de la concepción de lo teleológico en la Crítica de la Facultad de Juzgar. En primer lugar, Kant reconoce la diferencia entre una aproximación teleológica y una teológica:

[P]orque en la discusión que se refieren a meros conocimientos naturales y cuanto éstos alcanzan (donde es del todo conveniente expresarse teleológicamente), no encuentro aconsejable seguir un lenguaje teológico. Han de señalarse con todo cuidado los límites de cada modo de conocimientos (Kant [1788] 2006b, p. 209).

Los límites de los que nos habla Kant abordan la relación íntima entre una visión teleológica de la naturaleza y su eventual desenlace como una prueba de la existencia de Dios: para el filósofo este paso no es válido. En consecuencia, el modo de agencia discutido en el párrafo anterior descarta la posibilidad de una mente divina que pone los fines en la naturaleza y sus criaturas; estamos ante una forma de teleología de la cual presumimos que reside de forma exclusiva en la naturaleza. No obstante, afirmar que hay principios teleológicos en la naturaleza sólo es posible en tanto tenemos acceso a alguna forma de experiencia en la cual se instancie dicho principio:

Con todo, el concepto de un ser organizado es éste: un ser material que es posible sólo mediante la vinculación de todo aquello que está contenido en él, recíprocamente como fin y como medio (en realidad, cualquier anatomista, como fisiólogo, parte de este concepto). Una fuerza fundamental, mediante la que se obraría una organización, debe, en consecuencia, ser pensada como una causa que obra según fines y, desde luego, de manera que estos fines deben ponerse con fundamento por la posibilidad del efecto. Pero sólo conocemos fuerzas semejantes, según su fundamento de determinación mediante la experiencia, en nosotros mismos; a saber: en nuestro entendimiento y voluntad, como una causa de la posibilidad de cierto producto dispuesto por completo según fines; a saber: la obra de arte (Kant [1788] 2006b, p. 212).

He aquí la entrada en escena de la analogía entre el arte y la naturaleza como recurso epistémico que nos permite acceder y fundamentar una concepción teleológica de esta última. De igual forma, Kant argumentará, en este mismo texto, la necesidad de dicha concepción apelando a la libertad y los fines prácticos. El elemento crucial en esta segunda línea de defensa se centra en nuestra experiencia de la realización de fines, cuyo origen reside en la voluntad, en el orden físico de la naturaleza, como es el

\footnotetext{
${ }^{11}$ Una traducción previa de este mismo artículo, en lugar de hablar de 'semillas increadas', utiliza el término 'gérmenes innatos', por ejemplo en Kant ([1785] 1958, p. 80), el cual resulta más acorde con la terminología que usamos a lo largo de nuestro artículo.
} 
hecho, aunque aparentemente trivial, de ayudar a alguien a levantarse luego de haberse caído porque lo consideramos moralmente apropiado y bueno. La libertad, propia del orden de la razón práctica, realiza sus fines en el ámbito de la naturaleza, del mundo físico -el dominio de la razón pura-. Pese a que esta última idea constituye un eje fundamental de discusión del pensamiento kantiano en su pretensión de ser un sistema filosófico total, un sistema en el que la necesidad de la naturaleza se ligue a la libertad de la voluntad, nos enfocaremos en la analogía entre arte y naturaleza por ser ella una de las ideas más productivas y controvertibles en el desarrollo argumentativo de la Crítica de la Facultad de Juzgar.

Antes de pasar a la exposición particular de lo teleológico en la Crítica de la Facultad de Juzgar, consideramos prudente ofrecer, de forma muy breve, el panorama general de la obra. Ella consta de dos partes, la crítica del juicio estético y la del juicio teleológico, y un apéndice sobre la metodología del juicio teleológico. Puede que a primera vista dicha división no informe mucho; sin embargo, esta estructura puede ser esclarecida teniendo en cuenta algunos de los puntos que ya hemos enfatizado en los párrafos anteriores. En primer lugar, ¿por qué conjuntar en una misma obra dos temas tan aparentemente dispares como la belleza y el arte con la teleología y los organismos? La respuesta, de forma muy escueta, descansa sobre la analogía entre arte y naturaleza que Kant plantea en 1788, pese a que él había empezado a escribir la Crítica de la Facultad de Juzgar justo después de terminar la Crítica de la Razón Práctica, en 1787 (ver Zammito 1992 para un esbozo de cronología detallado del desarrollo de dicha obra). En segundo lugar, ¿por qué incluir un apéndice sobre la metodología del juicio teleológico y no del estético? Porque el juicio estético, encargado de discernir lo bello, solamente apela a la relación armónica de nuestras facultades (entendimiento, razón e imaginación), de modo que lo bello no es concebido como un juicio objetivo acerca de las cosas, sino que describe la forma como su apariencia nos afecta, i.e. es meramente subjetivo. Por su parte, el juicio teleológico, aunque también tiene tintes subjetivos, tiene una pretensión de objetividad relacionada con el tipo de objetos que estudia, i.e. los organismos, entidades naturales que, en principio, deberían estar sujetas a la legislación de la naturaleza. Por tanto, se hace necesario reconocer sus alcances en tanto que puede tomarse como un discurso objetivo sobre el mundo. Particularmente, la mayor preocupación kantiana es, como ya lo habíamos señalado con el texto de 1785 , la posibilidad de derivar del juicio teleológico una prueba de la existencia de Dios.

A partir de la analogía entre arte y naturaleza trataremos de discernir y derivar algunos de los conceptos más importantes relacionados con el organismo, así como sus restricciones dentro de la empresa crítica. De hecho, sería conveniente empezar con estas últimas. La analogía tal y como está propuesta en el texto de 1788 casi coincide con lo que Zammito (1992, pp. 151-177) ha denominado el segundo momento de la composición de la Crítica de la Facultad de Juzgar o "Giro cognitivo". De acuerdo con la cronología ofrecida por Zammito, este momento ocurre en los albores del año 1789 y consiste en la inclusión de una novedad epistemológica dentro del sistema crítico kantiano: el descubrimiento (o formulación, si se prefiere) de los juicios reflexivos basados en máximas regulativas. Una máxima es un principio heurístico, i.e., un supuesto que nosotros, como sujetos cognoscentes, debemos imponer a los objetos de estudio para poder aprehenderlos y dar cuenta de ellos pese a que no es posible tener una experiencia objetiva (bajo una ley necesaria y universal) de dichos principios. Cuando hacemos uso de estas máximas de la razón, el tipo de juicios que se produce es reflexivos, i.e. juicios que siempre remiten al sujeto como fuente de aquello que se discierne sobre la naturaleza y que no podemos decir que es una propiedad objetiva de ella. Por ejemplo, la teleología es una máxima que da lugar a juicios reflexivos, pues, como veremos más adelante, la concepción de los organismos como fines naturales no está provista de una experiencia empírica que dé cuenta de ello, sino que lo pensamos porque recurrimos a la analogía de la naturaleza con el arte: suponemos que en la naturaleza, de alguna manera, los fines funcionan de forma similar a como lo hacen en nuestra voluntad y acciones. A los juicios reflexivos se les contraponen los juicios determinantes, i.e. aquellos que siguen leyes universales de la naturaleza, concordando así con las facultades de la razón y del entendimiento, y que nos aseguran un conocimiento objetivo de ella. 
Como vemos, de entrada la analogía pone de manifiesto una de las peculiaridades del juicio teleológico: su carácter reflexivo o regulativo, más no constitutivo. Kant invoca el uso de esta analogía en la sección VIII de la introducción de la Crítica de la Facultad de Juzgar:

[0] bien a través de la naturaleza, en su técnica (como ocurre con los cuerpos organizados), cuando colocamos bajo ella a nuestro concepto de fin al enjuiciar su producto, en cuyo caso no se representa simplemente la finalidad [Zweckmässigkeit] de la naturaleza en la forma de la cosa, sino este producto suyo como fin de la naturaleza [Naturzwecke] (Kant [1790] 2003, p. 139).

Ya Kant se había referido a esta idea en la primera introducción de la Crítica de la Facultad de Juzgar, publicada por vez primera en 1914, donde nos dice que la presentación de la naturaleza como arte no implica una ampliación de la filosofía sino que funge como principio de investigación de la naturaleza (heurístico) y sólo afecta nuestra concepción de ella, mas no a la naturaleza misma. Como lo pondría más adelante:

Ciertamente, esta analogía [entre naturaleza y arte] no amplía realmente nuestro conocimiento de los objetos de la naturaleza, pero sí nuestro concepto de ella, pues lleva del mero mecanismo al concepto de una naturaleza en tanto que arte, lo cual invita a profundas investigaciones sobre la posibilidad de una forma semejante ([1790] 1987, §23, pp. 201-202). ${ }^{12}$

La analogía exhibe, en un primer nivel, la necesidad de contemplar la noción de finalidad al momento de juzgar tanto productos del arte como de la naturaleza. No obstante, los primeros requieren un tipo de finalidad que es meramente formal, mientras que los segundos refieren a una finalidad real o material. La finalidad formal es aquella en la cual la representación del objeto como un todo precede a la producción del mismo, i.e. el efecto determina y precede las causas del objeto ([1790] 1987, §10). La material, por su parte, retoma a la formal e incluye relaciones de producción entre el todo y las partes: ${ }^{13}$ un todo produce otro todo, un todo se produce a sí mismo, y el todo produce y mantiene partes que, a su vez, ayudan al sostenimiento del todo ([1790] 1987, §64). Kant lo ejemplifica con un árbol: el árbol produce otros árboles similares, el árbol se produce a sí mismo a partir de una semilla y el árbol produce hojas, las cuales son fundamentales para el mantenimiento del árbol; estas relaciones pueden trasladarse a otros ejemplos, tales como los animales o, incluso, las células. A estas entidades cuya experiencia empírica requiere la inclusión de esta noción de finalidad material, Kant las denomina fines naturales.

A partir de esta distinción entre los conceptos de finalidad se torna evidente el segundo nivel de la analogía, así como la divergencia notoria entre la producción artística y la natural: en tanto que en la naturaleza y en el arte se hace patente una técnica, es necesario localizar e identificar al agente que se apropia de dicha técnica y la ejecuta. Si en el lado del arte contamos con el genio-artista ([1790] 1987, §45-49), ¿cuál sería su equivalente en el lado de la naturaleza? Ya Kant nos había advertido que una concepción teleológica de la naturaleza no es suficiente para afirmar la existencia de Dios; además, en la misma Crítica de la Facultad de Juzgar, él nos dice que no es posible decir que Dios es el creador de los organismos y de la naturaleza pues caeríamos en un círculo vicioso en el cual los fines que percibimos en los organismos son puestos ahí por Dios, al tiempo que esos fines son la prueba de su existencia y poder ([1790] 1987, §68). Esta profunda divergencia entre los elementos que conforman la analogía se convierte en su punto de quiebre, pues, como bien lo expuso Robert E. Butts (1990, p.15), la analogía tiene como presupuesto indiscutible un acceso y un conocimiento perfecto de nuestra capacidad de actuar de conformidad con fines (derivados de la voluntad), a lo cual Zammito (2006, p. 760) agrega que el punto central de la analogía no es tanto la obra de arte sino el artista, i.e. la agencia humana. Sin

\footnotetext{
${ }^{12}$ Todas las referencias a la Crítica de la Facultad de Juzgar están indicadas por el número de parágrafo y la página de la traducción consultada.

${ }^{13}$ De acuerdo con Huneman (2006a, 2006b, p. 656), el cambio efectuado por Kant del léxico usual sobre teleología que utilizaba de forma copiosa medios y fines a relaciones entre partes y todo es crucial para comprender cómo Kant se aleja de una noción de teleología como utilidad (en la cual siempre hay referencia a un tercero para quien resulta beneficioso dicho fin) para concentrarse en la teleología como algo inmanente a los organismos, carente de referentes externos que no sea el de la reproducción y la herencia del linaje. Aquí el cambio lexical aparece como un indicador de cambio conceptual.
} 
embargo, lo que en principio se nos presenta como el límite de la analogía resulta ser, en cambio, su sentido; no en vano, este movimiento le permite a Kant reforzar el concepto de fin natural como ajeno a toda forma de causalidad o imposición externa, dándole un peso aún mayor a su concepción de lo teleológico como máxima regulativa de la razón, pues un fin natural, un organismo,

No resulta explicable ni tan siquiera pensable conforme a ninguna analogía física, o sea, potencia natural, que nos sea conocida e incluso, como nosotros mismos formamos parte de la naturaleza en su sentido más alto, tampoco resulta explicable ni pensable mediante una analogía que se corresponda con el arte humano ([1790] 1987, §65, p. 354).

En consecuencia, la auto-productividad de los fines naturales sienta las bases para su definitiva escisión de una visión estrictamente mecánica:

Así pues, un ser organizado no es una mera máquina, pues ésta tiene tan sólo una fuerza motriz, sino que una posee una fuerza configuradora, una fuerza capaz de transmitirse a materias que no la tiene, (organizándolas), una fuerza configuradora que se propaga y no cabe explicar únicamente por la capacidad motriz (por el mecanismo). ([1790] 1987, §65, p. 353)

La fuerza configuradora es lo que nos sirve de puente directo con el concepto de epigénesis y, de forma muy particular, con la obra de Blumenbach.

\section{La posibilidad de la epigénesis: entre la filosofía natural y la embriología}

La epigénesis, de manera general y como proceso biológico, corresponde a los pasos de un desarrollo embrionario gradual a partir de materia homogénea localizada en el huevo fertilizado que a través del tiempo conforma las características heterogéneas y particulares de las estructuras de los seres vivos. El transcurrir de cada paso en el desarrollo depende de que los procesos que están formando determinadas estructuras se cumplan como un antecedente necesario para el inicio de las formas posteriores en el organismo. Entonces, el desarrollo de las estructuras iniciales es condición del desarrollo de las formas siguientes y así sucesivamente, para que al final el organismo conforme un todo que tiene sentido gracias a las partes y viceversa, situación que ha representado en gran medida el espíritu de la embriología y la filosofía natural desde el s. XVIII y que incluso simpatiza con posturas sobre embriología, biología del desarrollo y teoría de sistemas del desarrollo generadas en el s. XX (ver Esposito 2013, Gilbert 2000, 2002, Gilbert \& Sarkar 2000, Oyama 2000a, 2000b, 2010, Thompson 1942, Waddington 1940, 1956, 1957, 1966, 1968, por mencionar algunas obras). Las partes tienen sentido en el organismo y éste tiene sentido gracias a ellas. Así, la mirada a la comprensión histórica y filosófica de la epigénesis aquí expuesta es concreta. Se sitúa en el contexto sobre las discusiones, a partir de los s. XVII y XVIII, acerca de cómo se generan ${ }^{14}$ los organismos, donde este proceso biológico suele identificarse por el antagonismo entre posturas preformistas y epigenéticas. Por tanto, el papel de la epigénesis en la propuesta kantiana se ubica al interior de una tensión cuyo sentido emerge desde una óptica reciente de la historia de la biología: el debate entre preformismo y epigénesis.

Dado que tanto la relectura como la reescritura proporcionan dinamismo a la generación de conocimiento, nuestro objetivo es resaltar los matices en el diálogo que se dio entre la empresa crítica kantiana y los discursos embriológicos de su época, en lugar de sólo analizar la lectura kantiana o las narrativas biológicas por separado. De hecho, el compromiso de Kant con las ciencias de la vida jugó un papel más sustancial en su filosofía trascendental del reconocido hasta ahora (Zammito 2003, p. 73) e, incluso, hay cierta originalidad filosófica en su compromiso profundo con los discursos científicos de su época. En específico, simpatizamos con la postura de Robert J. Richards (1992, 2002), Zammito (2003), Clark Zumbach (1984) y Gerd Buchdahl (1981), quienes enfatizan que a partir de la década de 1780 la filosofía kantiana toma forma en términos de su interacción con las prácticas biológicas de su

\footnotetext{
${ }^{14}$ Hablar de teorías de la 'generación' en el s. XVII y subsecuentes implica reconocer que no hay una separación entre el estudio de la reproducción/herencia, así como de la génesis, desarrollo embrionario y ciclo de vida de los organismos. Dicha escisión aparecería en los albores del s. XX con la separación radical entre genética y embriología.
} 
época, en específico con la embriología, de forma tal que ella se reestructura a la luz de las formas de producción de conocimiento científico.

Sin embargo, la relación con la epigénesis no es inmediata; aquello que Kant deseaba formular, en las primeras instancias de la empresa crítica, era una analogía entre preformación y filosofía trascendental; ${ }^{15}$ la epigénesis no aparecía en ninguno de sus textos antes de 1787 (ver Zammito 2003, p. 86). Por otro lado, tampoco se contaba con acuerdos sobre el significado de la epigénesis en el s. XVIII (ver Moscoso 1995, Richards 1992, Roe 1979, 1981), con lo cual las polémicas y comprensión en la transformación de esta filosofía natural de la primera a la tercera Crítica son un punto de análisis que no muchas perspectivas interesadas en Kant han decidido contrastar.

A partir del momento en el cual Kant se interesa de forma seria en el estudio de lo vivo, en particular de las razas humanas, se produce un cambio significativo: si el estándar estaba en la ciencia natural newtoniana, aquí la filosofía kantiana es novedosa porque demanda que, además de la concepción físico-mecánica, sea necesario explicar y entender la epigénesis de lo vivo. Ahora bien, sin necesidad de caer en consideraciones vitalistas, cuando miramos a un problema biológico frente a uno mecánico nos topamos con el hecho de que hay un concepto de causalidad en el primero que no está presente en el segundo (Zumbach 1984, p. 81). Éste es el terreno fértil en el que brotan los conceptos de fin natural y ser organizado. Desde un punto de vista filosófico, la interacción con la epigénesis fue crucial. Cuando Kant en sus inicios se inclinó más por analogías de tipo preformista, su interacción profunda con la embriología lo llevó a proponer que cada organismo contenía una cantidad de gérmenes [Keime] distintos y de predisposiciones naturales [Naturanlagen], donde los primeros eran la fuente de cambios en los órganos y los segundos ocasionaban cambios en el desarrollo (como lo vimos en el primer texto sobre las razas humanas). Posteriormente, Kant conciliaría dicha postura con una perspectiva matizada que involucró tanto al preformismo como a la epigénesis: una relación entre educto y producto en un proceso inmanente (ver Zammito 2003).

En 1781, Blumenbach propondría la idea de la Bildungstrieb (fuerza formativa) ${ }^{16}$ y con ella su confirmación de la epigénesis (Richards 2002, p. 212, Zammito 2003, p. 75). Gracias a esta postulación, Kant siguió de cerca los conocimientos generados en la embriología. Es a raíz de esta interacción que comienzan a dibujarse las tensiones en el sistema kantiano, de manera que resultaba complicado que el estudio de la vida tuviera sentido bajo la lupa de una causalidad tipo newtoniana, con lo cual Buchdahl (1981) interpreta un movimiento kantiano de "holgura" entre lo constitutivo y lo regulativo, una argumentación elemental entre lo trascendental y lo empírico, para que las nuevas influencias embriológicas cobraran algún sentido, el cual se distanciaba un poco de la primera Crítica, al menos en la forma de entender a los seres vivos. En la "Crítica del Juicio Teleológico", Kant da cuenta de su lectura de Blumenbach al emplear la noción de 'auto-organización', ${ }^{17}$ donde un organismo debe estar organizado y ser auto-organizado, donde la epigénesis (en su sentido biológico) requiere causalidad interdependiente, situación corroborada de manera experimental en la embriología. Así, los organismos son distintos de las meras máquinas y los artefactos, ya que conforman una reciprocidad simétrica partes-todo, donde el todo (i.e. el organismo) es el fin en sí mismo, una causalidad particular de lo vivo, es decir, con arreglo a fines (Zweckmässigkeit). Con lo anterior, los organismos pueden explicarse y conocerse sensu Kant únicamente cuando se emplea la idea de finalidad como un principio, pero sólo se refiere a un modelo epistemológico necesario. Los organismos entonces son fines naturales que no pueden asimilarse de manera sencilla en el modelo de causalidad de la física newtoniana.

\footnotetext{
${ }^{15}$ La primera edición de la Crítica de la Razón Pura (1781) contiene la mayor cantidad de elementos preformacionistas. Para cuando Kant la revisa y publica la segunda edición, incluye cambios significativos con respecto a este tema: compara a la razón con un sistema de epigénesis, al tiempo que se deslinda, en buena medida, de las consideraciones y lenguaje preformacionistas.

${ }^{16} \mathrm{Al}$ final de la sección sobre teleología vimos que Kant también hablaba de una fuerza configuradora. Sin embargo, el término alemán era Kraft en lugar de Trieb. Este último es mejor traducido como impulso; sin embargo, es muy común que en español se conserve fuerza por la estrecha relación que hay entre la Bildungstrieb como una fuerza análoga a la gravitación universal de Newton.

17 También hay una referencia directa a Blumenbach en Kant ([1790] 1987, §81).
} 
Es ineludible que Kant dialogó de manera constante con el conocimiento científico de su época. En particular, la relación de la Crítica de la Facultad de Juzgar con las prácticas biológicas del s. XVIII ha sido analizada, de forma relativamente reciente, desde distintas perspectivas históricas y filosóficas (ver Lenoir 1980, Buchdahl 1981, Zumbach 1984, Sloan 2001, Richards 2002 y Zammito 2003; Mensch 2013 constituye un ejemplo de exploración profunda de la relación entre la empresa crítica total y el conocimiento biológico). En contraste, el estudio histórico de la epigénesis es un tema ampliamente estudiado, sobre todo en la dicotomía que forma con el preformismo, en el marco de las teorías sobre la generación de los organismos. El debate entre epigénesis y preformismo a finales del s. XVII fue material para diversas polémicas metafísicas y metodológicas: Kant se mantuvo próximo a este contexto guiado por sus preocupaciones particulares en la empresa crítica, las cuales fueron intersectadas por la controversia entre mecanicismo y vitalismo, así como su negación de cualquier tufo hilozoísta o panteísta.

Uno de los puntos cruciales de la manera en la cual la epigénesis cimbró a la filosofía kantiana se localiza entre los años de 1784 y 1790, en la cual refleja mucha premura acerca de sus grandes reservas acerca de las implicaciones hilozoístas, Johann Gottfried von Herder (1959) y Georg Forster (2013), y vitalistas, ${ }^{18}$ ocasionando una reflexión profunda que le permitió discriminar los usos constitutivos y regulativos de la razón (Zammito 2003, p. 73). En este escenario de conflictos, la idea de la epigénesis en Blumenbach lo motivó a tratar de aproximar este marco embriológico de la organización viva con la física newtoniana. Dada la fama del uso de fuerzas sensu Newton, no es extraño que Blumenbach formulara su Bildungstrieb en relación con la epigénesis en 1781, donde explícitamente niega cualquier apelación a gérmenes, i.e. Keime, contrastando con la relación que Kant propuso inicialmente entre preformismo y epigénesis, mencionada al inicio de este apartado. En la década de 1780 se estableció una comunicación entre ambos autores, de modo que para 1789 Blumenbach mandó a Kant una copia de la segunda edición de su ensayo sobre la Bildungstrieb, donde se exponía el concepto de epigénesis atravesado por una aproximación metodológica que reflejaba la influencia kantiana para lograr una distinción entre lo mecánico y lo teleológico (Zammito 2003).

En esta tónica, cuando Kant escribe la Crítica de la Facultad de Juzgar ya las conversaciones con la epigénesis desde la embriología han trastocado algunas de sus ideas. En este punto, Kant omitió las alusiones a Keime y se percibe un uso constante del término Anlagen (ver Sloan 2001). Con un Kant más familiarizado con la preformación en la primera Crítica, el análisis de la epigénesis para la década de 1780 posibilitó entender que la naturaleza era más grande que su versión física, desbordando así los límites newtonianos con los que Kant inicialmente deseaba estructurarle. Para 1790 la Bildungstrieb en Kant reubicó el orden constitutivo al orden regulativo, dado que el sistema de la epigénesis no explica el origen de las formas de los organismos, pero dice más de lo que no sabemos acerca de él (Zammito 2003, p. 88). No obstante, pese a la persuasión de la obra de Blumenbach y a que la Bildungstrieb se formulara como una fuerza inspirada en la gravedad newtoniana, Kant insistió en que la ciencia natural fidedigna requiere fundamentos en algún tipo de universalidad y necesidad a priori. Una de las formas en que Kant estructuró el proyecto crítico consistió en demostrar cómo las leyes empíricas necesitaban ser enmarcadas -o, en la formulación más tolerante de Buchdahl (1981), "anidadas" - en los principios trascendentales a priori a través de los cuales la experiencia sólo era posible para la humanidad, al tiempo que dichas leyes empíricas no podían simplemente deducirse a partir de principios a priori de la razón. La práctica e influencia de proceder (newtonianamente) con base en la ley de la gravitación universal es un paso que muestra el procedimiento (o el intento en el caso de Blumenbach y su Bildungstrieb) de transformar meras reglas empíricas en leyes necesarias (ver Friedman 1991), un privilegio exclusivo para el ámbito de la física. Pero, después del intercambio entre Blumenbach y Kant, era evidente que la organización de la naturaleza no era análoga con ninguna causalidad concebida en aquella época, lo que colocó particularidades en el horizonte de lo vivo que esta interacción fue capaz de mostrar. Lo vivo, forzado a interpretarse a la luz de la majestuosidad del sistema causal de la física newtoniana, debía permanecer contenido en la esfera regulativa de la razón y

${ }^{18}$ Ver Kant [1790] 1987, §65. 
el juicio reflexivo, como parte de un nivel empírico más bajo de conceptos y leyes hacia unos más generales que alcanzan una clasificación completa dentro de un sistema jerárquico. En este sentido, siguiendo a Michael Friedman (1991, pp. 90-91) es sólo a partir de la ley empírica del nivel más alto que se encuentran los fundamentos metafísicos de la ciencia natural.

Bajo este canon de estructuración, buscar conocimiento sobre los organismos resultó irreconciliable con base en la posibilidad trascendental de la experiencia objetiva. Sin embargo, de manera más caritativa, los organismos no son asimilables en su totalidad a las leyes empíricas de la misma forma que los artefactos y mecanismos, en palabras de Kant, "[e]s totalmente cierto que ni por asomo podemos llegar a conocer suficientemente los seres organizados ni su posibilidad interna según principios meramente mecánicos de la naturaleza, ni mucho menos acertar a explicárnoslos" ([1790] 1987, §75, p. 382). Por lo tanto, esta confrontación con lo vivo, en particular con la epigénesis estudiada por Blumenbach, implicó que Kant, en su Crítica de la Facultad de Juzgar, indagara por un camino de fuerzas y causas no reducibles a la física, sugiriendo ciertas bases para la legitimación y reconocimiento de la singularidad en las ciencias de la vida. Con todo, Kant siempre fue firme respecto a los cuestionamientos sobre el origen último de la organización o de la Bildungstrieb, porque tal reflexión requería un compromiso desde la metafísica y no era una discusión que pudieran solucionar los límites del entendimiento humano desde la epistemología. A fin de cuentas, uno de los aspectos que Kant detectó en la propuesta de Blumenbach y que le pareció congruente con su propia postura filosófica fue la negativa de este último a respaldar una forma de epigénesis absoluta o radical en la cual la materia orgánica tenía su origen en la materia inorgánica: para Kant siempre era necesario reconocer la existencia de una organización previa a partir de la cual se gestase la organización siguiente en la reproducción, herencia y desarrollo ([1790] 1987, §81). ${ }^{19}$ Es por esta razón que Kant, en el mismo parágrafo de la cita anterior, también habla de la epigénesis como preformismo genérico: las predisposiciones propias de una especie se encuentran desde el principio de la embriogénesis y son sus relaciones con el ambiente las que delinean el proceso de desarrollo a seguir, aun cuando los mecanismos involucrados se describan desde una perspectiva física (Huneman 2006b).

\section{Conclusiones. La necesidad del diálogo entre filosofía y ciencia}

Nuestro texto es una mirada sobre dos problemas esenciales para la comprensión kantiana de los organismos: por un lado, la teleología como condición de posibilidad del darle sentido a los organismos en la naturaleza ${ }^{20}$ sin tener que recurrir a salvaguardas teológicas tan en boga en el s. XVIII; por otro, cómo Kant se desenvolvió teóricamente, primero, con el preformismo, después con la epigénesis y, en general, su propuesta de diálogo entre la filosofía y la ciencia. De hecho, este último adquiere gran relevancia en el periodo estudiado de Kant pues hay una retroalimentación constante entre sus imposiciones y limitaciones epistemológicas (la empresa crítica, los juicios constitutivos y regulativos), la ciencia de su época (la física newtoniana, las teorías embriológicas, la controversia entre preformismo y epigénesis), y los supuestos metafísicos que defiende en su obra (la renuente negativa a cualquier forma de hilozoísmo, la separación infranqueable entre materia orgánica e inorgánica, la

\footnotetext{
${ }^{19}$ Hans Driesch (1914, pp. 83-86) advierte que la lectura kantiana de Blumenbach no fue adecuada, pues la incorporación de la idea de una organización previa u original para dar cuenta de la siguiente limita el factor productivo y vitalista de la Bildungstrieb. Este malentendido se suma a aquellos otros que Richards (2000) y Zammito (2012) han señalado en la relación Kant-Blumenbach.

${ }^{20}$ Hasta aquí sólo se ha tenido en cuenta la relación estrecha que hay entre teleología, organismo y ciencias de la vida, la cual es profundizada por Marcel Quarfood (2006). Sin embargo, la noción de lo teleológico en Kant tiene además otro cariz complementario que nació en la primera crítica: el principio teleológico como un principio racional que unifica y sistematiza nuestro conocimiento de la naturaleza y la posibilidad de nuestras acciones en ella (ver Davis 1895, Steigerwald 2013). Entre estas dos nociones de teleología surge un conflicto que puede comprometer la unidad del sistema kantiano y cuya exposición se encuentra en la antinomia del juicio teleológico: Joan Steigerwald (2013) muestra cómo en la antinomia lo que se juega es la complementariedad de las dos nociones pues, por un lado, la teleología como unidad de la naturaleza se deriva de la actividad de la razón en su faceta práctica, que funge como punto de inicio para la analogía entre arte y naturaleza, lo cual, por otro lado, termina por mostrarnos cómo la noción de finalidad inherente a los organismos es categóricamente distinta de aquella que derivamos de los productos del arte: hay una tensión o antagonismo en las dos forma de teleología. Infortunadamente, el espacio para el presente artículo es limitado y no podemos ofrecer un análisis más detallado de esta interesante controversia.
} 
necesidad de las fuerzas como elementos explicativos legítimos). En sintonía con Haraway (1988, p. 593) las y los actores vienen en muchas formas maravillosas, de esta manera, los informes de un mundo "real" no dependen de la lógica de "descubrimiento" sino de una relación social cargada de poder de "conversación".

Para varias personas (sensu Zammito 2003) esta parte de la empresa crítica no merece ser tomada en cuenta. No obstante, nuestra propuesta es abrir conversaciones porque es inevitable considerar que las reflexiones kantianas, cuyo punto más álgido podemos encontrar en 1790 con la publicación de la Crítica de la Facultad de Juzgar, se esforzaron en trazar una analogía de su propia filosofía trascendental con la epigénesis embriológica y viceversa, con lo cual se evidencia el compromiso entre ambas posturas para dilucidar los fenómenos de la vida. Resta aún un mapeo futuro sobre cómo estas ideas dialogan con nuestras prácticas contemporáneas.

Existe un trasfondo filosófico en el conocimiento de las ciencias de la vida actuales que si bien no siempre está de manera consciente entre las personas practicantes abre la posibilidad de diálogo. Como se expuso aquí, tenemos una comprensión concreta de los conceptos teleología y epigénesis sin adscribirlos exclusivamente a la filosofía de la biología, o filosofía en general, o a la biología, sino a las influencias que ambas disciplinas tuvieron entre sí. Dado que la perspectiva situada se posiciona frente a la totalidad del conocimiento, la manera en la que Kant se vio influenciado por la embriología funciona como un ejemplo concreto que invita a una visión interdisciplinaria de una filosofía para la biología, donde discusiones entre ambas perspectivas encuentren más puntos de intersección dinámica en la generación de conocimiento.

Bibliografía

Berg, H. (2013), "The Wolffian Roots of Kant's Teleology", Studies in History and Philosophy of Biological and Biomedical Sciences 44(4): 724-734.

Buchdahl, G. (1984), "Reduction-Realization: A Key to the Structure of Kant's Thought", Philosophical Topics 12(2): 29 98.

Butts, R.E. (1990), "Teleology and Scientific Method in Kant's Critique of Judgment”, Noûs 24: 1-16.

Davis, C.L. (1895), “Kant's Teleology”, Proceedings of the Aristotelian Society 3(2): 65-86.

Driesch, H. (1914), The History and Theory of Vitalism, London: MacMillan \& Co.

Esposito, M. (2013), Romantic Biology 1890-1945, London: Pickering \& Chatto.

Forster, G. (2013), "Something More about the Human Races", en Mikkelsen, J. (ed.), Kant and the Concept of Race, Albany: SUNY Press, pp. 146-167.

Friedman, M. (1991), "Regulative and Constitutive", Southern Journal of Philosophy 30: 73-102.

Gilbert, S. (2000), “Diachronic Biology meets Evo-Devo: CH Waddington's Approach to Evolutionary Developmental Biology", American Zoologist 40(5): 729-737.

Gilbert, S. (2002), "The Genome in its Ecological Context", Annals of the New York Academy of Sciences 981(1): 202-218.

Gilbert, S. y S. Sarkar (2000), "Embracing Complexity: Organicism for the 21st Century", Developmental Dynamics 219(1): $1-9$.

Haraway, D. (1988), "Situated Knowledges: The Science Question in Feminism and the Privilege of Partial Perspective", Feminist Studies 14(3): 575-599.

Herder, J.G. (1959), Ideas para una filosofía de la historia de la humanidad, Buenos Aires: Losada.

Huneman, P. (2006a), "From the Critique of Judgment to the Hermeneutics of Nature: Sketching the Fate of Philosophy of Nature after Kant", Continental Philosophy Review 39(1): 1-34.

Huneman, P. (2006b), “Naturalising Purpose: From Comparative Anatomy to the 'Adventure of Reason'”, Studies in History and Philosophy of Biological and Biomedical Sciences 37: 649-674. 
Kant, I. ([1790] 1987), Critique of Judgment, Indianápolis: Hackett Publishing Co.

Kant, I. ([1786] 1993), Primeros principios metafísicos de la ciencia de la naturaleza, México: IIF-UNAM.

Kant, I. ([1790] 2003), Crítica del Discernimiento, Madrid: Antonio Machado Libros.

Kant, I. ([1777] 2007), “Of the Different Races of Human Beings”, en Zöller, G. y R.B. Lauder (eds.), Anthropology, History and Education, Cambridge: Cambridge University Press, pp. 84-97.

Kant, I. ([1785] 1958), "Definición de la raza humana”, en Estiú, E. (trad.), Filosofía de la Historia, Buenos Aires: Editorial Nova, pp. 66-84.

Kant, I. ([1785] 2006a), "Determinación del concepto de una raza humana”, en Alcoriza, J. y A. Lastra (trads.), En defensa de la Ilustración, Barcelona: Alba Editorial, pp. 93-113.

Kant, I. ([1788] 2006b), "Sobre el uso de principios teleológicos en la filosofía”, en Alcoriza, J. y A. Lastra (trads.), En defensa de la Ilustración, Barcelona: Alba Editorial, pp. 183-217.

Lenoir, T. (1980), "Kant, Blumenbach, and Vital Materialism in German Biology”, Isis 71, 77-108.

Lerussi, N.A. (2012), "Acerca de los esbozos para una teoría filogenética kantiana (según la Crítica de la Facultad de Juzgar $\$ \S 80$ y 81)”, Metatheoria 3(1): 73-92.

Lerussi, N.A. (2013), “La teoría kantiana de las razas y el origen de la epigénesis”, Studia Kantiana 15: 85-102.

Mensch, J. (2013), Kant's Organiscism. Epigenesis and the Development of Critical Philosophy, Chicago: The University of Chicago Press.

Moscoso, J. (1995), “Experimentos de regeneración animal: 1686-1765 ¿Cómo defender la preexistencia?”, Dynamis: Acta Hispanica ad Medicinae Scientiarumque Historiam Illustrandam 15: 341-373.

Oyama, S. (2000a), The Ontogeny of Information: Developmental Systems and Evolution, Durham: Duke University Press.

Oyama, S. (2000b), Evolution's Eye: A Systems View of the Biology-Culture Divide, Durham: Duke University Press.

Quarfood, M. (2006), "Kant on Biological Teleology: Towards a Two-Level Interpretation”, Studies in History and Philosophy of Biological and Biomedical Sciences 37(4): 735-747.

Richards, R.J. (1992), The Meaning of Evolution: The Morphological Construction and Ideological Reconstruction of Darwin's Theory, Chicago: University of Chicago Press.

Richards, R.J. (2000), "Kant and Blumenbach on the Bildungstrieb: A Historical Misunderstanding", Studies in History and Philosophy of Biological and Biomedical Sciences 31(1): 11-32.

Richards, R.J. (2002), The Romantic Conception of Life: Science and Philosophy in the Age of Goethe, Chicago: University of Chicago Press.

Roe, S. (1979), "Rationalism and Embryology: Caspar Friedrich Wolff's Theory of Epigenesis", Journal of the History of Biology 12(1): 1-43.

Sloan, P. (1981), Matter, Life, and Generation: 18th Century Embryology and the Haller-Wolff Debate, Cambridge: Cambridge University Press.

Sloan, P. (2002), "Preforming the categories: Kant and eighteenth-century generation theory", Journal of the History of Philosophy 2: 229-253.

Steigerwald, J. (2013), "Natural Purposes and the Purposiveness of Nature: The Antinomy of the Teleological Power of Judgment”, en Van de Vijver, G. y B. Demarest (eds.), Objectivity after Kant: Its Meaning, Its Limitations, Its Fateful Omissions, Hildesheim: Georg Olms Verlag, pp. 83-97.

Waddington, C.H. (1940), Organisers and Genes, Cambridge: Cambridge University Press.

Waddington, C.H. (1957), The Strategy of The Genes. A Discussion of Some Aspects of Theoretical Biology. London: George Allen \& Unwin.

Waddington, C.H. (1968), Towards a Theoretical Biology 1: Prolegomena, Edinburgh: Edinburgh University Press.

Thompson, D.W. (1942), On Growth and Form, Cambridge: Cambridge University Press.

Zammito, J.H. (1992), The Genesis of Kant's Critique of Judgment, Chicago: University of Chicago Press. 
Zammito, J.H. (2003), “This Inscrutable Principle of an Original Organization': Epigenesis and 'Looseness of Fit' in Kant's Philosophy of Science", Studies in History and Philosophy of Science 34: 73-109.

Zammito, J.H. (2006), "Teleology Then and Now: The Question of Kant's Relevance for Contemporary Controversies over Function in Biology", Studies in History and Philosophy of Biological and Biomedical Sciences 37: 748-70.

Zammito, J.H. (2012), "The Lenoir Thesis Revisited: Blumenbach and Kant", Studies in History and Philosophy of Biological and Biomedical Sciences 43(1): 120-32.

Zumbach, C. (1984), The Transcendent Science: Kant's Conception of Biological Methodology, The Hague: Nijhoff. 